\section{Questión}

Periodismo / Comunicación ISSN 1669-6581
- Av. $44 \mathrm{~N}^{\circ} 676,1^{\circ}$ piso

CP 1900 - La Plata - Argentina

(i) www.perio.unlp.edu.ar/question

El arte de generar comunidad o sobre la comunicación en tiempos de pandemia

María Aurelia Di Berardino

DOI: https://doi.org/10.24215/16696581e291

\title{
El arte de generar comunidad o sobre la comunicación en tiempos de pandemia
}

\section{The art of community-building or communication in times of pandemic}

María Aurelia Di Berardino1 / aurelia.diberardino@presi.unlp.edu.ar

FaHCE-IdIHCS-CONICET-UNLP-CIC

Profesora y doctora en Filosofía por la UNLP. Docente por elección, epistemóloga por convicción, comunicadora en acción.

La experiencia compartida es el mayor de los bienes humanos

John Dewey

\footnotetext{
${ }^{1}$ Algunas reflexiones contenidas en este texto, en particular, las dedicadas a la obra de John Dewey, son un pequeño extracto de: Di Berardino, M.A.Arte, experiencia y democracia: una vuelta a La opinión pública y sus problemas a la luz del concepto de caridad de Gianni Vattimo. En Pablo Quintanilla, Claudio Viale (editores), El pensamiento pragmatista en la actualidad: Conocimiento, lenguaje, religión, estética y política. Lima: Fondo Editorial de la Pontificia Universidad Católica del Perú. Octubre 2015, pp.369-381.
} 
Resumen

El objetivo de esta intervención es proponer una reflexión filosófica sobre las condiciones actuales utilizando como recurso el encuentro de dos propuestas de autores pragmatistas. Por un lado, el estudio de las emociones beligerantes en la obra de William James y, por el otro, el alcance de la opinión pública desde la perspectiva de John Dewey. Entrelaza a ambos autores, la necesidad de buscar una salida a este presente con arte e imaginación.

Palabras claves: pandemia, emociones, opinión, comunicación

Ecos en tiempos de pandemia

Uno de los proverbios más sabios que he escuchado es aquel que articula la siguiente prohibición: No abras la boca si no estás segurx de que lo que vas a decir es más hermoso que el silencio. Casi sin precedentes personales me encamino, sin dudas ni pesar, hacia una paradoja: nada de lo que diga puede ser más bello que el silencio y sin embargo, quiero decir algo. Tal vez responda a un impulso vital, quizá no sea otra cosa que la reiteración de una práctica profesional adquirida. Sin embargo, el teclado de mi ya casi obsoleta computadora le exige continuidad a este pensamiento desordenado que supe conseguir en cuarentena. Es probable que ni yo misma sospeche hacia donde irá a parar mi verborragia recién estrenada pero lo cierto es que se me desbordan las palabras y no hago más que dar vueltas sobre un par de ideas que ya de tan viejas, me resultan nuevas.

A veces ocurre entonces que sencillamente, se vuelve necesario decir. Este es uno de esos momentos. Un cuerpo no resiste tanta vida/muerte desbocándose ahí afuera. Y en eso andará cada quien, obsesionándose alternativamente con alguna idea para conjurar la saturación de noticias: de las verdaderas, de las falsas, de las irrisorias, de las patéticas... Mucho de todo, poco de nada: el territorio conocido se escurre en el ripio de una memoria amenazada. Eso que hemos sido, aquello que hemos conseguido, esto que nos avergüenza, lo de más allá que nos 
enorgullece... Somos memoria detenida, sujeta a un presente que se dilata en todas las direcciones, infinito presente, carcelario presente.

Algunas de nuestras obsesiones se curan en salud, y en este caso la salud tiene forma de escritura, de conversación en suspenso con quienes se acerquen a descubrir los trazos de otras murmuraciones. La mía, en este caso, vuelve a repensar cosas que ya he dicho, escrito, sugerido. Más que todo, he sugerido y mucho en mis clases, año tras año -y a propósito de quién sabe qué disparador- ciertas lecturas de inesperada lucidez.

El último disparador -pero no el único- fue la lectura de filósofxs que, al calor de la pandemia, no pudieron como quien escribe, contener la palabra. Un filósofo en particular despertó todas las alarmas porque trasladó una preocupación vieja al escenario contemporáneo. Me refiero a Gabriel Markus (2020), filósofo neo-realista alemán que sugirió, o más bien vociferó, la siguiente proclama: necesitamos una pandemia metafísica. ¡Pero ni que estuviéramos faltos de incidentes como para soportar otro que, por lo demás, no es sencillo imaginar! ¿O acaso sabemos cómo sería exactamente una pandemia de estas características? ¿Incluiría su sintomatología, tal vez, una fiebre repentina que provocase explicaciones acertadísimas del porqué hay algo y no más bien, nada?

Lejos de cualquier elucubración, lo cierto es que lo que Markus plantea es bastante sensato. Señala que la pandemia ha logrado un nivel de solidaridad inusitado: los epidemiólogos han conseguido, digamos, disciplinar a millones de personas bajo la égida de un peligro inminente, invisible, voraz. Sin embargo, la diana del reclamo no apunta al disciplinamiento, sino al reconocimiento de que el mecanismo solidario se activa $-y$ solo se activa- frente a una amenaza. ¿Será que somos incapaces de arrimarnos al fogón a menos que un par de fieras, unos cuantos seres munidos de palos y hachas o una fantasmagórica enfermedad, nos acorrale? Como dicen en el pueblo, parece que somxs todxs hijxs del rigor.

Esta respuesta rápida es solo para andar por casa, hay tanta agua corriendo bajo este puente que creo que vale la pena detenerse a pensar en ello. Decía, entonces, que la proclama de Markus me llevó a revisitar viejas ideas y en este caso, de un viejo conocido. Corría el año 1906 y William James fue invitado a dar una conferencia en la Universidad de Stanford. Cuatro años más tarde, la publicación de aquella presentación se convirtió en un éxito de ventas. "El 
equivalente moral de la guerra", tal el título de la publicación, superó ampliamente las expectativas de los dos bandos involucrados en la discusión: por un lado, los pacificistas quienes contaban con el mismo James entre los suyos, y por el otro, los militaristas. Ahora bien, ¿cómo pudo un texto conciliar esos antagonismos? El mérito de James reside, entiendo, no tanto en lograr que Ixs lectorxs aprueben todos los aspectos involucrados en su argumentación, sino en presentar el problema de tal forma que solo queda como solución, salirse del problema. Algo así como la tan recurrente figuración de que finalmente, del laberinto se sale por arriba. La estrategia de James es justamente ésa: trepar los muros y preguntarse algo diferente. Pero miremos un poco de cerca de qué va esta idea jamesiana:

La argumentación del psicólogo y filósofo pragmatista pretende cancelar la disputa tradicional (pacifismo/militarismo) valiéndose del papel central que tienen en el propio planteo determinados tipos de emociones. Según James, la guerra despierta emociones que ninguna otra instancia social o individual consigue promover. Los aspectos estéticos (del orden de lo sentido) que se manifiestan en un estado de belicosidad no pueden ni suprimirse ni neutralizarse por medio de razones 0 , lo que es igual, los juicios desapasionados acerca de la conveniencia moral de un estado semejante no logran cancelar ciertas emociones asociadas a él. Para James, no se trata tanto de buscar argumentos para explicar por qué la guerra es indeseable y la paz sí lo es. El autor propone un reemplazo de la guerra en la medida en que ésta es la única instancia que moviliza aspectos peculiares de la emoción. El comienzo de su discurso contiene algunas claves de su reflexión:

La guerra contra la guerra no va ser una excursión ni una fiesta de acampada. Los sentimientos militares están demasiado arraigados como para abandonar su lugar entre nuestros ideales, hasta que no se ofrezcan nuevos mejores sustitutos que la gloria y la vergüenza que les advienen tanto a las naciones como a los individuos de las altas y bajas esferas de la política así como de las vicisitudes del comercio (James, [1910] 2004).

Según James, la guerra amalgama muchas emociones que bien podrían ser capitalizadas y ganadas en una propuesta moral e intelectual diferente. Por lo demás, los argumentos pacifistas no podrían más que fracasar, a juicio de nuestro autor, por el simple hecho de que la 
humanidad no ha encontrado nada que hiciera las veces de la guerra para promover y aunar los intereses variados y heterogéneos presentes en los miembros de una sociedad.

La utopía social de James no pretende cancelar la propia estética de las emociones militaristas, sino mejor, reencausar su energía. Al menos desde la modernidad, sostiene, se ha dudado de la guerra como razón suficiente o como fin para dar cabida a aquellos sentimientos anclados en el espíritu militar (cohesión social, orgullo, etc.). Sin embargo, la duda sobre la finalidad de la guerra operó un cambio solamente en las facetas morales o intelectuales de la emoción, dejando inalterada la "emocionalidad o esteticidad" de la emoción. En este sentido, la atención de James se desplaza hacia la misma condición recalcitrante de algunas de las emociones humanas. Así, no basta con postular que la guerra no es el fin de una sociedad, porque tampoco lo es para James. $Y$ tampoco es suficiente reemplazar el fin, tal como acaso admitiría el giro moderno de esa disputa: plantearnos por caso, dice James, que en lugar de someter a los pueblos por medio de la guerra, pudiese lograrse lo mismo a instancias del comercio. El problema, lejos de cancelarse, resurge bajo otros ropajes: las energías de los hombres, que se vuelven carne con la guerra, y sólo con ella, recrudecen también en la situación de comprar y vender. El mercado impone otro vasallaje que oxigena el ideal de superioridad de algunos pueblos sobre otros, por mencionar uno solo de los aspectos involucrados en la lógica imperialista.

La situación a la que presta atención James es entonces, la siguiente: puedo variar los fines comunitarios, comprender que la cohesión social debería proceder con atención a otros fines que no sean la guerra o el vasallaje vía mercado. Pero si no puedo modificar la "sustancia" movilizada por aquellos fines, ergo, no habré suprimido ni la guerra ni el imperio. Tarde o temprano, retornarán, porque todo lo que habremos logrado será reprimir, ocultar -y siempre momentáneamente- la esteticidad de la emoción beligerante. En otros términos, la propuesta de James pretende iluminar precisamente ese punto de conflicto, hacerlo evidente, mostrar que las emociones en juego existen y perduran. $Y$ nuevamente, que su persistencia se debe a la represión mal entendida, a la insistencia en sentir menos. La conferencia de Stanford pretendía hurgar en las energías dormidas de los hombres, aquellas que aparecen en estado de alerta, cuando la alteridad (hombres, virus, etc.) representa una amenaza y toda la cuestión reside en resolver la disputa entre nosotrxs y ellxs. Esas energías extras, emociones que la sociedad 
siempre termina enalteciendo y que reproducen los intereses más egoístas, surgen -por fuerza de la costumbre- cuando el temor amenaza. Con todo, en la utopía de James, las energías bien podrían generarse de una manera diferente. El autor entiende que hay ideas (políticas, científicas, filosóficas, etc.) que funcionan precisamente movilizando nuestra voluntad y en consecuencia, reconduciendo la acción. Dichas ideas no hacen más que orientar energías hasta entonces dormidas y provocar la eventual gestación de sociedades distintas.

La apuesta de James entonces, como les decía, procura que los miembros de la sociedad no sientan menos, sino que piensen más. Después de todo, el juicio desapasionado oculta las emociones, las niega, las rechaza, y por ese mismo movimiento -aunque parezca paradójicose permite que operen, que tomen cuerpo en acciones cada vez más irreflexivas, irracionales, pero profundamente arraigadas en el temple beligerante que, más que una excepción, constituye la regla del mundo occidental. James aborda las emociones en toda su integridad, como marcas o estimaciones instintivas, en la medida en que ellas tienen su ancla en un mundo temible y ciego, a fin de que puedan así resultar encausadas mediante sucesivas apreciaciones. Resulta, en consecuencia, que la alternativa guerra-paz debería ser descartada puesto que esta "oposición" no es más que el ocultamiento de la ubicuidad de la guerra: ya como guerra efectiva, ya como guerra demorada, potencial. Cuerpo y espíritu, guerra y paz, son expresiones de una lucha individual y colectiva, que resultaría evitable toda vez que las emociones involucradas en cada caso pudieran surgir u ofrecieran ocasión a cada unx de trabajar (constructivamente a favor de) la tela sin costuras en que consiste la experiencia humana.

Ahora bien, llegados a este punto, recuperaré aquellos aspectos del análisis de William James que hacen al argumento general de mi presente intervención. Frente a la solicitud de los pacificistas de que el autor encontrase un argumento a favor de la paz, James propone desestimar la estrategia. Lo hace pensando en que todo argumento, toda estructura racional sobre el problema, descansa en unas cuantas incomprensiones. Una de ellas, la incapacidad de entender que no somos animales racionales, generadorxs de juicios. Somos un organismo complejo, atravesado de reacciones, emociones, reconfiguraciones que podríamos denominar "instintivas". Aunque aquí ya nos desborda una segunda incomprensión, hablar de instinto es una manera un tanto simple de explicar que nuestras respuestas habituales al entorno -ya casi 
automáticas- son el producto de un largo trayecto evolutivo donde naturaleza y cultura son indiscernibles. Pretender que la razón sea una suerte de producto allende a nuestras posibilidades de respuesta, es reincidir en una miopía cartesiana. No podemos pensar por fuera de nuestros cuerpos, no podemos dejar de sentir algunas cosas. Sí podemos pensar más acerca de lo que circula en los márgenes y en el interior de nuestra experiencia encarnada. La ventaja del texto de James es devolvernos una mirada humana, preñada de significación de piel y huesos. Nos vuelve a interpelar como la proclama de Markus: ¿qué es lo que hará las veces de una pandemia bajo el reino del terror? O también, ¿qué mundo queremos habitar mañana?

Sin andar mucho, por todas partes se nos cuela la metáfora beligerante: se le ha declarado la guerra a la pandemia y habrá que vencerla. Ahí, justamente ahí, es donde vuelvo a destacar la lucidez de James porque parece que no hay nada más por hacer para promover la cohesión, el encuentro y la solidaridad que encolumnarnos en una cruzada contra el mal que vino de oriente. Si no hay nada más a la vista quiere decir que no hemos avanzado mucho en relación a la comprensión de nuestras emociones más arraigadas. Eso sí, a la guerra vamos todxs, como si la muerte inminente nos hiciera más humanxs. El enemigo (la alteridad) garantiza el alistamiento tras unas filas comunes que todo lo que tienen de común es el espanto.

Pero ese alistarse tras ciertas filas tiene una vuelta de tuerca: no es inocente, ni automático. Muy por el contrario, a la reacción primerísima y primitiva de identificar una otredad amenazante y responder comunitariamente, se le suma la multiplicidad de voces que llegan desde los distintos medios de comunicación y que insisten/refuerzan la metáfora militar.

El punto es que este incidente nos deja a escasos metros de la preocupación jamesiana. Esto es, cuando todo pase (porque el optimismo no se le niega a nadie), ¿a qué estado de cosas volveremos? ¿Quiénes seremos el día después? ¿Cuáles serán nuestros lazos comunes? ¿A quiénes tendremos que odiar para volvernos solidarixs con quienes odian lo mismo?

Para esbozar una respuesta a las murmuraciones anteriores, dibujo un trayecto posible. Este trayecto antojadizo me dice que si comencé por James bien podría continuar por otro pragmatista, John Dewey. Arbitrario o deliberado, lo cierto es que ambos autores nos conducen de la mano de dos reflexiones de fondo: el rol de las emociones (James) y el papel de los mass 
media en la construcción de una determinada opinión pública (Dewey). Una reflexión lleva a la otra, puesto que las emociones beligerantes siempre latentes son animadas, provocadas, estimuladas, por los medios de comunicación.

Comunicar: el arte de generar una experiencia compartida

Desde que el término opinión pública fuera acuñado por J.J.Rousseau, muchas fueron las formas por la que los autores comprometidos con la temática trataron de dotar de significado a la expresión misma. De suerte que, como han sostenido algunos, la opinión pública se parece a los elefantes: pueden ser difíciles de definir, pero es fácil reconocer uno. Así, hay teorías que van desde la voluntad común que concebía Ferdinand Tönnies (1902), hasta las que suscriben a una perspectiva normativa como la de Jürgen Habermas en la contemporaneidad. Una de ellas, desarrollada a principios de los años 20 , la de Walter Lippmann, tuvo su eco en lo que hasta podríamos señalar como un texto de respuesta crítica a esa propuesta. Nos referimos al texto de John Dewey, La opinión pública y sus problemas (1927) donde se deja ver la insistencia del autor pragmatista por desacreditar toda instancia dualista que separe de manera tajante la emotividad de la razón, lo privado de lo público, el individuo y la sociedad. Una estrategia que acumula páginas de sus escritos para concretar -paradójicamente- la utopía de deliberar acerca de nuestros deseos, fines y valores eventualmente comunes.

El debate Lippmann-Dewey fue uno bastante decisivo para comprender por un lado, la relación entre opinión pública y democracia y, por el otro, para la institución de leyes sobre los medios de comunicación. En ese contexto y en parte como consecuencia de la polémica, la propuesta de Dewey quedó descartada como pensamiento político, social y epistemológico. Como bien señala Ramón del Castillo en el prólogo de la edición española, las perspectivas de ambos polemistas no podría ser más distinta:

El asunto, sin embargo, no consistía en oponer el mundo de la información al de la emoción, ni la acción de un Estado burocrático frente a la irracionalidad del público. A diferencia de Lippmann, Dewey no separaba tajantemente opinión y conocimiento, hábito y pensamiento. Para Dewey, la opinión no era solo el reino de los prejuicios, las impresiones vagas, los lugares 
comunes, las emociones fáciles. Ciertamente, las opiniones son sólo eso, opiniones, ideas a medio formar o ideas sin aclarar, si las mantenemos al margen de la discusión abierta. Sometidas a esa prueba, en cambio, pueden llegar a demostrar si son adecuadas o provechosas con relación a una situación problemática. Sea cual sea el grado de verdad que contengan, solo lo podremos descubrir sometiéndolas al tribunal de la esfera pública (Dewey: 2008, p.15).

En estrecha conexión con todo su pensamiento filosófico, Dewey se detiene a pensar en las particularidades de lo que se considera opinión pública (o "el público"). Su pregunta fundamental es quiénes constituyen un público y cómo se logra esta configuración. Para el pedagogo pragmatista, son los ciudadanos comunes quienes podrían llegar a ser un público, o quizá, muchos. Más precisamente, la cuestión es quiénes y cómo habrán de constituir el tipo de asociación comunitaria donde el deseo coincida con la acción; en cuyo marco, entendimiento, emoción e inteligencia anuden medios y fines en una trama razonada. El único problema es que el quién y el cómo no existen, no son nada más que potencialidades, instancias que se darán a sí mismas su forma en el momento en que se generen. Dicho de otro modo, mientras que autores como Gianni Vattimo (2010) entienden a la opinión pública como el costado inanalizable de la democracia y exigen para ésta un valor que la sostenga, a saber, el de caridad, Dewey se hace cargo de lo que pueda ser esa opinión para mostrar que una y la misma cosa son el público y la democracia.

Sabemos que para Dewey la democracia es una experiencia comunitaria más que una conformación política. Democracia es un modo de estar en el mundo, es la plena conciencia del alcance de las consecuencias de las acciones en el todo de la comunidad. Esas acciones reclaman una mediación que siempre es puesta en manos de quienes componen unas instituciones prontas a garantizar que los intereses de todxs consoliden los valores compartidos. Estos valores surgen de la experiencia y existe la posibilidad de que se comuniquen y compartan. Dichos valores no tienen otra provincia que la inmediatez con que se aprehenden los bienes y cuya mediación simbólica desarma en reflexión y crítica. Solo la imaginación, que siempre es personal y artística logra recrear la unión vivida de las potencialidades de la experiencia. Así, escribe: 
En el arte como experiencia, la actualidad y la posibilidad o idealidad, lo nuevo y lo viejo, el material objetivo y la respuesta personal, lo individual y lo universal, lo superficial y lo profundo, lo sensible y la significación, se integran en una experiencia que transfigura la significación que tienen cuando la reflexión las aísla (Dewey, 2008: p.335).

Si nos detenemos en la cita precedente, podemos observar que resuena el viejo James todo el tiempo. De hecho, Dewey está amalgamando lo vivido, el orden de la experiencia sentida, con la reflexión, con ese repliegue de la razón sobre lo sensible. Es un movimiento que exige pensar más y no sentir menos. Y para ello, John Dewey, conjura al arte. Ahora bien, esta imaginación creadora común a poetas y filósofos, solo necesita ser direccionada. En Opinión Pública y sus problemas Dewey sostiene que el público, lejos de gestarse pasivamente, es un movimiento que surge de la inconformidad de una minoría, incluso una minoría de una sola persona. No tiene sustancia hasta tanto tenga a su alcance los medios apropiados para oponerse al hábito del que se nutren los Estados o los medios de comunicación. La profusión de medios no garantiza el aumento de comunicación, porque para que ésta exista es preciso el esfuerzo imaginario que haga de lo posible la chispa que encienda la organización de un público en vistas de un fin deseado. El público no es un mito dice Dewey: hay público solo en el caso de que se logre, a través del arte, vincular simbólicamente, lo presente y lo ausente en una unidad perdida.

¿De qué está hecha esa "unidad perdida"? Aquello que se comparte es la deseabilidad de una forma comunitaria posible: dicho proyecto comunitario es sugerido por el arte; mientras que el cómo es un asunto que requiere de la investigación social. Para Dewey, este tipo de investigación tiene dos caras como Jano: por un lado, analiza las noticias y, en su faceta erudita, reflexiona sobre los medios para la investigación. Los resultados obtenidos han de ser divulgados, y el hecho mismo de comunicarlos es exactamente lo mismo que formar la opinión pública. El análisis de las noticias es equiparable a quitarle el carácter contingente y abrupto a lo que ocurre. El investigador social tiene que hacer las paces entre la noticia y su dimensión social, esto es, a qué fines responde, cuáles son sus consecuencias y en qué pasado se inscribe la misma. El significado total queda reabsorbido por esta doble direccionalidad pasado/futuro que todo acontecimiento ha de tener si es que quiere ser comunicable y por lo tanto, público. La opinión pública no puede decidir en el vacío: cuando lo hace es síntoma 
ineludible de manipulación, propaganda, censura y fomento del secreto en manos de quienes ostentan el poder político y/o económico:

El catastrofismo, el sensacionalismo, especialmente crímenes, accidentes, disputas familiares, choques y conflictos personales, son las formas más obvias de ruptura de la continuidad; suministran, sin duda, el elemento de impacto emocional más próximo al mundo de la sensación; son la noticia por excelencia, aunque únicamente la fecha del periódico nos pueda informar de si ocurrieron el año pasado o éste; aunque estén tan completamente aisladas de sus conexiones (Dewey, 2004: p.154).

De suerte que para Dewey, la opinión pública es el requisito para la vida comunitaria y la vida comunitaria por excelencia, donde la continuidad admite la proyección hacia un ideal de sociedad posible, es la democrática. Hablar de opinión pública en cualquier otro contexto, es desconocer la relación entre vida común, divulgación efectiva del conocimiento, decisión colectiva y democracia.

En este juego de conocimientos que se entrelazan con el sentimiento de "comunidad", el arte antecede a cualquier gestación del público, y por lo mismo, de la democracia. El filósofo debe escuchar tanto la voz de quienes investigan los acontecimientos como la imaginación desbordada del artista que trae al mundo, las auténticas novedades (posibilidades):

Las palabras proporcionan un registro de lo que ha sucedido y ofrecen orientaciones para las acciones futuras particulares. La literatura transmite el sentido del pasado, significativo en la experiencia presente, y profetiza el movimiento más amplio del futuro. Sólo la visión imaginativa explicita las posibilidades contenidas en la trama de lo actual. Las primeras agitaciones de insatisfacción y las primeras insinuaciones de un futuro mejor se encuentran siempre en las obras de arte. La impregnación de las artes característicamente nuevas de un período, con un sentido de valores diferentes a los que prevalecían, es la razón por la cual los conservadores encuentran que tal arte es inmoral y sórdido...El cambio en el clima de la imaginación es precursor de los cambios que afectan a algo más que a los detalles de la vida (Dewey, 2008: p.391). 
La auténtica crítica social no la hace la investigación social, ni siquiera el filósofo: es el artista quien descubre imaginativamente las posibilidades que contrastan con las condiciones actuales y en la medida que denuncia este descubrimiento, produce crítica (Dewey, 2008: p.393).

El filósofo de Dewey, preocupado por la continuidad de la experiencia, deja para el arte, la difícil tarea de consumar la creación de un público, porque además, el artista se completa en la medida en que tiene un otro a quien expresarle sus "descubrimientos":

Liberar las potencialidades de los individuos y educar artísticamente es el requisito previo para entender la continuidad de nuestras acciones y deseos, conducir la emoción por las vías de la opinión razonada y compartir una vivencia. En la medida de lo posible, le hacemos decir a Dewey, una vivencia democrática. Hablar de opinión pública como si el público no fuera más que una masa desorganizada es no creer en las posibilidades que cantan los bardos en el foro. Una opinión pública desorganizada es una contradicción en los términos, lo que hay es un alejamiento de la experiencia en su sentido primitivo.

Y aquí podríamos pensar, en cuán deliberada puede ser la distorsión de la opinión pública y cuánto esa distorsión nos aleja de una vida comunitaria plena en el sentido de Dewey. Presuponer todo el tiempo que la opinión pública es algo estático pero a la vez voluble, dispensa de toda responsabilidad a quienes comunican, puesto que todo lo que hay que hacer es montar un espectáculo para que parezca que cambia todo cuando no cambia nada.

Hombres necios que acusáis al futuro sin razón

Con el ánimo de procurar una conclusión provisoria, valga esta pequeña recuperación de lo dicho hasta aquí. Como un mapa que necesita repasarse antes de internarnos en un bosque, retrocedamos al punto de partida de mi trasnochada reflexión pandémica. Les decía que alguien por allí pedía a gritos una pandemia metafísica. $Y$ al hacerlo intentaba señalar un aspecto que suele permanecer oculto: nada parece cohesionar más que un peligro inminente. Sin embargo, cuando el peligro se aleja, no hay argamasa capaz de gestar, para decirlo en mis términos, una comunidad. Esto es, una conexión solidaria donde los fines (razones, pensados, consensuados) encaminan nuestras acciones futuras. Comentaba también que a propósito de 
este pedido inusitado de Gabriel Markus (tal el nombre de nuestro filósofo angustiado), no pude más que recordar viejas cuestiones relativas al problema de las emociones. Después de todo el temor, es una de nuestras emociones más atávicas. $Y$ es por ello que repuse algunas reflexiones de William James a propósito de las emociones beligerantes, esas que, como bien comprende Markus, aglutinan conciencias y sociedades. Esa reflexión jamesiana refuerza la idea de que nada ganamos barriendo bajo la alfombra nuestros sentires. Muy por el contrario, cuando nos pensamos por fuera de las dinámicas dualistas modernas (cuerpo y mente, emoción y razón, medios y fines, individuo y sociedad), se nos hace comprensible la necesidad de observar las relaciones entre esos pares ordenados. La mirada sobre la intimidad de nuestros procesos nos devuelve una conciencia que entiendo, puede resultar interesante para pensarnos a partir de esta suspensión del tiempo condicionada por un virus.

Sin embargo, esta recuperación de la argumentación jamesiana hizo posible hurgar en el álbum familiar del pragmatismo clásico. Así fue como llegamos a la propuesta de John Dewey en su Opinión Pública y sus problemas. Es una parada obligatoria en mi mapa de ruta, aquí y ahora. Y esto por varios motivos. Uno de ellos es que la proclama Markus/James nos deja con las emociones a flor de piel para ser pensadas. Pero falta un aspecto más que exige reflexión: las emociones que aglutinan conciencias y sociedades son fomentadas en muchos casos, por los medios de comunicación. Esa constatación nos ahorra el andar ingenuo: promover ciertas emociones, exaltarlas, disponerlas las 24 horas del día, sin mediar análisis alguno, no hace más que ocultar las múltiples potencialidades de las que somos capaces, como individuos y como sociedad. Pueden ustedes buscar y creánme, encontrarán una profusión de titulares donde se nos dice que cuando todo este termine, volveremos a ser Ixs mismxs. Donde se nos advierte que esta detención del tiempo no hará mella en nuestras habituales maneras de estar en el mundo. Se encontrará la vacuna y cada quien volverá a sus transitados escenarios.

Pero justamente allí es donde se vuelve crucial algunas instancias del pensamiento deweyano: no se trata de sentir menos. Aunque tampoco se trata de sentir más. La cuestión reside en generar una práctica discursiva razonada que vuelva posible una experiencia compartida. Dicha experiencia no es una experiencia del ahora: es una proyección de lo que seremos mañana, a la luz de lo que hemos sido. Por ello es que necesitamos la imaginación para conjeturar un estado de cosas que todavía no es: se vuelve preciso propiciar, artísticamente, 
otras posibilidades. En buena medida, en eso consiste el arte de comunicar. Y en gran parte también, en eso consiste la responsabilidad de quienes por alguna razón u otra, habitamos el tiempo generando vínculos, gestando comunidad.

Si perdemos de vista estos aspectos que hacen mundos, entonces, habremos de declarar la muerte del futuro. Porque ningún futuro que se precie de tal puede permitirse el lujo de anunciarse ya pasado. ¡Que Ixs necixs dejen de anunciar cosas y se preparen para imaginar!

Todo arte comunica porque expresa. Nos permite participar vívida y hondamente en significados a los que éramos sordos o a los que sólo oíamos dejándoles seguir su tránsito. Porque la comunicación no consiste en anunciar cosas, aun cuando se digan con el énfasis de una gran sonoridad, sino que es un proceso creador de participación que hace común lo que era aislado y singular; y parte del milagro que realiza, es que, al comunicarse, la transmisión de significado da cuerpo y definición a la experiencia, tanto del que expresa como de todos aquellos que escuchan (Dewey, 2008: p.275).

\section{Bibliografía}

Dewey, J. (2004), La opinión pública y sus problemas. Madrid, Editorial Morata. Traducción de Roc Filella.

Dewey, J. (2008), El arte como experiencia, Barcelona, Paidós. Traducción de Jordi Claramonte.

James, W. "The Moral Equivalent of War" (1906) en Burkhardt F., Bowers F. y Skrupskelis I. (eds.), The Works of William James, Cambridge, MA, Harvard University Press, 1982, IX, pp. 162-173. Versión en español on line: https://www.unav.es/gep/TheMoralEquivalentOfWar.html

James, W. "The Energies of Men" (1906) en Burkhardt F., Bowers F. y Skrupskelis I. (eds.), The Works of William James, Cambridge, MA, Harvard University Press, 1982, IX, pp. 129-146. Version en español on line: https:/www.unav.es/gep/EnergiasHombres.html

Vattimo, G. (2010), Adiós a la verdad, Barcelona, Gedisa. Traducción de María Teresa d’Meza. 